\title{
The Relationship Between Different Parenting Typologies in Fathers and Mothers and Children's Anxiety
}

\author{
Ana Beato $^{1} \cdot$ Ana Isabel Pereira ${ }^{1}$ Luísa Barros ${ }^{1} \cdot$ Peter Muris $^{2}$
}

Published online: 28 November 2015

(c) Springer Science+Business Media New York 2015

\begin{abstract}
Research on the role of parental rearing behaviors in the development of children's anxiety problems has predominantly adopted a dimensional approach studying the effects of isolated parenting behaviors such as overprotection and rejection, while mainly focusing on the mother. Our study was set up to identify parenting typologies of both mothers and fathers, and to explore their relationship with children's anxiety symptoms. Threehundred-and-ninety non-clinical Portuguese children aged 8-12 years completed a self-report questionnaire on anxiety disorder symptoms, while their fathers (27-64 years of age) and mothers (24-65 years of age) filled in two scales on parental rearing behaviors as well as an index of parental anxiety. Cluster analysis revealed three parenting typologies that were similar for mothers and fathers, and were labeled as overinvolved, disengaged, and supportive parenting. Only the disengaged typology of mothers was associated with higher levels of anxiety symptoms on children. Disengaged parents and Overinvolved fathers were associated with higher levels of parental anxiety whereas overinvolved parents evidenced more anxiety/worry about the child. These results suggest that the study of parenting typologies, contextualized within a cultural background, are an invaluable approach because it can be used to explore the effects that different combinations of various parenting behaviors may have on childhood anxiety.
\end{abstract}

Ana Beato

anafilipabeato@gmail.com; anabeato@campus.ul.pt

1 Faculty of Psychology, University of Lisbon, Alameda da Universidade, 1649-013 Lisbon, Portugal

2 Faculty of Psychology and Neuroscience, Maastricht University, Maastricht, The Netherlands
Keywords Children anxiety $\cdot$ Parental anxiety $\cdot$ Parenting styles $\cdot$ Father-child relationship $\cdot$ Maternal disengagement

\section{Introduction}

Anxiety disorders are among the most common psychological disorders during childhood and adolescence. Epidemiological studies have found prevalence rates ranging between 2.6 and $41.2 \%$ in children before age 12 (for a review, see Cartwright-Hatton et al. 2006). Girls generally manifest higher rates of anxiety disorders than boys, and this gender difference becomes even more prominent during adolescence (Costello et al. 2004). Moreover, various studies highlight the negative outcomes of anxiety throughout the lifespan, including social and academic impairments (Wood 2006), physical complaints (Ginsburg et al. 2006), or secondary psychological disorders such as depression (Weissman et al. 2004).

Research has clearly shown that anxiety runs in families (Gar et al. 2005). For example, the children of anxious mothers are seven times more likely to develop an anxiety disorder than those who have non-anxious mothers (Turner et al. 1991). Conversely, parents of children with an anxiety disorder are more likely to experience anxiety themselves than parents of non-disordered children (Last et al. 1987). During the past three decades, many studies have focused on the mechanisms by which parents influence the development or maintenance of childhood anxiety problems (Eley 2001). This research points to a genetic transmission of anxiety, but it also highlights the role of family risk factors, such as insecure parent-child attachment, modeling of fearful behavior and avoidant strategies, parental anxiety, and negative parenting (Ballash et al. 2006). 
Theoretical models (e.g., Barlow 2002; Chorpita and Barlow 1998; Rapee 1997) highlight the role of parenting in the development and maintenance of childhood disorders. Research within the context of childhood anxiety has focused on three important parenting dimensions, namely warmth (which is concerned with acceptance, affection, and responsiveness towards the child), rejection (which refers to parental criticism, hostility, indifference, and negativity), and control (which has to do with the parents' intrusive regulation of children's emotions and behaviors) (McLeod et al. 2007). Warmth is considered as an important dimension because it is associated with responsive parenting, which promotes children's sense of security and control. Although some authors consider warmth and rejection as two ends of a unique continuum (Parker et al. 1979), others regard a lack of warmth simply as a facet of rejection (Benoit 2009). A negative rearing environment based on rejection and lack of warmth has been associated with children's internalizing problems, including anxiety (Bögels and Brechman-Toussaint 2006). According to Krohne (1992), children who are consistently exposed to negative feedback may develop threatening and hostile beliefs about the environment and perceptions of poor selfcompetence. Control is a complex concept that often includes interrelated subtypes (i.e., overinvolvement, intrusiveness, psychological control, behavioral control, and overprotection) and has consequently been operationalized in different ways. Overprotection is defined as a specific but also distinct dimension of control (see Pereira et al. 2013) and is characterized by excessive parental shielding (Holmbeck et al. 2002) and constant supervision of the child (Thomasgard and Metz 1993). Overprotective parenting is thought to be related to negative outcomes in children as it diminishes children's exposure to difficult situations, thereby hindering their opportunity to develop effective coping skills and a sense of mastery over the environment (Chorpita and Barlow 1998).

Numerous studies have indicated that the parents of anxious children and adolescents are characterized by a lack of warmth, high levels of rejection, and a strong inclination towards overprotecting (e.g., Barber 1996; Di Bartolo and Helt 2007; Gerlsma et al. 1990; Hudson 2013). Meta-analytic studies have provided some insight into the relative importance of these parental rearing dimensions. That is, McLeod, Wood and Weisz (2007) found a medium effect size of .52 for the association between parental overprotective control and child anxiety, which was clearly stronger than the association between parental rejection and child anxiety $(\mathrm{d}=.41$; for similar results, see: Van der Bruggen et al. 2008). Some authors posit that parental rejection may be more relevant for childhood depression, whereas parental overcontrol is more important in the context of young people's anxiety problems (Rapee 1997).
There are also indications that the relationship between children's anxiety and parenting may be reciprocal. For example, Rapee (1997) suggested that anxious reactions exhibited by children might increase parents' controlling behaviors.

Preceding research has also supported a link between children's and parental anxiety. Compared with non-anxious parents, parents with higher anxiety are found to be more withdrawn (Turner et al. 2003), more critical (Hirshfeld et al. 1997), overcontrolling (Bögels and Melick 2004), and less productively engaged in their interactions with the child (Woodruff-Borden et al. 2002) than nonanxious parents. Moreover, previous work has suggested the importance of analyzing parents' cognitive factors to comprehend the relationship between parental and children's anxiety. Anxious parents may have more negative perceptions concerning children's vulnerability and competency, which may justify their overprotective behavior towards the child (Rapee 2002; Thomasgard and Metz 1997). Therefore, parental worries about their child's vulnerability are also an important variable for understanding why some parents tend to overprotect and to discourage child's autonomy. A recent study observed that parental worry about children is strongly associated with parental overprotection (Pereira et al. 2014).

It is generally assumed that mothers and fathers play different roles in the development of childhood anxiety disorders. Fathers are considered to play an essential role with regard to the promotion of autonomy (Bögels and Phares 2008) through various mechanisms such as incentivizing their child to be independent and adventurous and encouraging children's behavioral coping based on bravery and risk-taking behaviors (Paquette 2004; Verhoeven et al. 2012), while mothers are more involved in providing emotional support, personal safety, and care (McBride and Mills 1993; Fliek et al. 2015). Gender roles may elicit these distinct parenting behaviors and thus influence children's anxiety in different ways. So far, however, most research has centered on mothers, while the studies that have addressed the independent effects of mother's and father's parenting on child anxiety have documented quite inconsistent results. Whereas some studies found a positive relationship between fathers' rearing behavior (in particular overprotection) and children's anxiety problems (e.g., Barrett et al. 2005; Bögels et al. 2008; Pereira et al. 2014), others have had difficulties in replicating such results (e.g., Hudson and Rapee 2002).

The age and gender of children are also considered as moderator variables in the relationship between parenting and child anxiety. Thus far, however, no conclusive results have been obtained regarding their effects. For instance, McLeod et al. (2007) found no moderation effect of children's age and gender on the link between parenting and 
childhood anxiety. Yet, the meta-analysis performed by van der Bruggen et al. (2008) found an increased effect of parental control on children's anxiety as they became older, and this was especially true in girls. According to Leaper (2002), parents may be more controlling of girls because they perceive higher anxiety levels in daughters than in sons. The clarification of the role of parental gender and children's age and gender in the association between parenting and child anxiety remains important. In particular, the dynamic coexistence of moderators needs further exploration. This can be illustrated by means of the study by Verhoeven, Bögels and van der Bruggen (2012), who noted parental gender differences in the relationship between parenting and child anxiety depending on the age of the child. More precisely, maternal overcontrol was found to be uniquely related to anxiety in elementary school children, whereas paternal overcontrol was related to anxiety during adolescence.

Most of the studies on the role of parenting in child anxiety have focused on specific parenting dimensions, such as warmth, rejection, and overcontrol, to study its links to this type of internalizing psychopathology in children. Although this dimensional approach has been useful in elucidating the unique links between such specific parenting behaviors and childhood anxiety, it is also true that in daily life, parents rarely rely on isolated behaviors but often combine various types of behaviors. According to Baumrind, Larzelere and Owens (2010), the study of parental patterns has benefits compared to analysis of the effects of single parental variables because "without certain other conditions being present the strength or direction of an expected parent-child relationship might well be altered" (p. 162). Thus, variable-centered approaches ignore how multiple parental behaviors occur simultaneously in a natural way and how the effects of a certain dimension depend on the presence or absence of other dimensions (Caron et al. 2006). For instance, high parental overprotection can have differential effects on the child's adjustment depending on whether it is combined with a warm or a rejecting parenting style. A study adopting a typological approach showed that the combination of overprotection and rejection ("affectionless control") was a better predictor of anxiety and depression in offspring than both dimensions in isolation (Parker 1983).

One of the pioneers of the typological approach in the study of parenting was Diana Baumrind (1971, 1989, 1991), who developed an extensive and longitudinal work with middle class white families to identify the familial antecedents of optimal competence in children and adolescents. Departing from two main dimensions of parents' behavior, responsiveness (rejection versus warmth) and demandingness (strict versus lack of behavioral control) (Maccoby and Martin 1983), a fourfold classification of parenting behavior was derived. Authoritative parents were both demanding and responsive, permissive parents were more responsive then they were demanding, authoritarian parents were demanding but not responsive and neglecting parents were neither demanding nor responsive. These four prototypes were present in different developmental periods and had different consequences for childreńs adaptation. Many posterior studies have replicated these main typologies and analyzed the relationship between these parenting patterns and children's adjustment. They have largely demonstrated that the authoritative type is associated with the most positive child outcomes, such as emotional stability, competence, and global adjustment (Mounts and Steinberg 1995; Steinberg et al. 1994; Weiss and Schwarz 1996). In the opposite direction, the neglecting pattern is associated with the worst child outcomes in various areas, such as academic, social, affective, and behavioral problems (e.g., Darling 1999; Radziszewska et al. 1996; Quintin 2001).

The present study had three main objectives. First, using a cluster analytic procedure, this study aimed to identify an empirical typology of parenting styles based on a variety of five critical parenting styles and behaviors (warmth, rejection, control, overprotection, and encouragement of approach behaviors). To identify possible variations in parenting styles as a function of gender, we conducted separate cluster analyses of the same parenting behaviors for mothers and fathers. Secondly, based on the empirically derived clusters, we investigated the relationships between maternal and paternal parenting typologies and children's anxiety symptoms. Finally we examined whether the parenting types differed on important children's demographic characteristics (age and sex), as well as parental characteristics (anxiety and parental worry concerning the child).

\section{Method}

\section{Participants}

The sample consisted of 390 school age children (175 boys and 215 girls) and their mothers and fathers. Their ages ranged from 8 to 12 years-old $(M=9.97, S D=.49)$. Children were in the 3rd to 6th grades at 13 public schools in the Lisbon (Portugal) metropolitan area. The mean age of the mothers was 39.61 years-old $(S D=5.68)$ and that of the fathers was 41.59 years $(S D=5.88)$. Approximately one-third of the mothers $(n=134,34.4 \%)$ and fathers $(n=180,32.1 \%)$ had completed secondary school, 94 $(24.4 \%)$ and $111(29.5 \%)$ had completed 9th grade or less, $57(14.6 \%)$ and $44(11.3 \%)$ had followed technical courses, and $96(24.7 \%)$ and $89(22.8 \%)$ had a university degree. For 9 mothers $(2.3 \%)$ and 17 fathers $(4.4 \%)$, the 
educational level was unknown. Nearly one-fifth of the children came from divorced parent families $(n=63$, $18.2 \%$ ) where both parents were involved in childrearing. Most families lived in urban or semi-urban areas (77.4 \%). The majority of families enjoyed a middle socio-economic status (SES; $n=241,61.8 \%$ ). The other families either had a low $(n=97,24.9 \%)$ or high SES $(n=52,13.4 \%)$.

\section{Procedures}

Data were collected within the context of a larger study on parenting and child anxiety. The project was approved by the National Data Protection Commission, the General Administration for Innovation and Curriculum Development in Lisbon, and the Deontology Committee of the Faculty of Psychology, University of Lisbon, Portugal. Consent was also obtained from school boards and teachers before conducting the study.

The parents of all of the children were first invited to complete a consent form indicating their agreement to participate in the study. More than half $(N=987,58 \%)$ agreed to participate, $18 \%$ refused, and $28 \%$ did not return the form. Questionnaires were then administered to the children during regular school classes. Confidentiality issues were explained and completion instructions were given to the children before the assessment session began. Parent questionnaires were sent to fathers and mothers through the children, completed at home independently, and returned to the researchers in sealed and separated envelopes via the school teachers. For the present study, a subsample of 390 children was selected from the recruited sample based on the inclusion criterion that both parents had returned and completed their questionnaires.

\section{Measures}

\section{Children's Anxiety Symptoms}

The screen for child anxiety related emotional disordersrevised (SCARED-R; Muris et al. 1999) is a self-report measure with 69 items assessing symptoms of all anxiety disorders that may occur in children according to the DSMIV (American Psychiatric Associations, 1994). Thus, the SCARED-R includes items referring to separation anxiety disorder ("I get scared when I sleep away from home"), generalized anxiety disorder ("I am nervous"), panic disorder ("When frightened, it is hard to breathe"), social phobia ("I don't like to be with people I don't know"), school phobia ("I don't like going to school"), specific phobia ("I am afraid of an animal that is not really dangerous"), obsessive-compulsive disorder ("I want things to be in a fixed order"), and acute or post-traumatic stress disorder ("I have frightening dreams about a very aversive event I once experienced"). Children indicate how frequently they experience each symptom on a 3-point Likert scale $(0=$ never, $1=$ sometimes, and $2=$ often $)$. Scores can be computed for each anxiety disorder and a total anxiety score can also be obtained. The Portuguese version of SCARED-R possesses good internal consistency and test-retest reliability, as well as adequate convergent and discriminant validity (Pereira et al. 2011). The internal consistency of the total scale, which was used in the present study, was excellent (Cronbach's alpha $=.94)$.

\section{Parenting Styles and Behaviors}

Two questionnaires were used to measure parental styles. The first scale was the Egna Minnen Beträffande Uppfostran (EMBU-P; Castro et al. 1997), a 42-item self-report questionnaire for measuring parental perceptions of their own child-rearing behaviors. More precisely, the EMBU-P measures three dimensions of rearing: (a) rejection ("Are you too stringent with your child?"), (b) emotional warmth ("Do you respect your child's opinions?") and (c) control ("Do you decide how your child should dress and about his/her appearance?"). Items are rated on a 4-point Likert scale $(1=$ No, never, $2=$ Yes, but seldom, $3=$ Yes, often, $4=$ Yes, most of the time). The Portuguese version of the instrument has shown acceptable internal consistency (Canavarro and Pereira 2007). In the current study, Cronbach's alphas of EMBU-P subscales for fathers and mothers also indicated sufficient to good internal consistency (Cronbach's alphas were .79 and .82 for emotional warmth, .74 and .70 for rejection, and .70 and .69 for control).

The second measure of parenting was the Parental Anxiety and Overprotection Scale (PAOS; Pereira et al. 2013), which is a 20-item scale that can be used to assess three dimensions: anxiety and worry about the child ("I wonder if my child is capable of defending herself in school"), overprotection ("I try to protect my child from everything that may scare him/her," "When my child is anxious, I try to calm him/her down immediately"), and encouragement of approach behaviors ("I tell my child that the best way to address his/her fears is facing them"). Parents are asked to rate how these statements correspond to how they usually behave towards the child, using a response ranging from 0 (None) to 4 (Very much). The scale has good psychometric qualities (Pereira et al. 2013). In this study, good internal consistency was obtained for fathers $\quad($ anxiety/worry $=.91, \quad$ overprotection $=.83$, encouragement of approach behaviors $=.83$ ) and for mothers $\quad($ anxiety/worry $=.90, \quad$ overprotection $=.85$, encouragement of approach behaviors $=.78$ ) . 


\section{Parental Anxiety}

The Brief Symptom Inventory (BSI; Derogatis 1982) was used to assess parents' anxiety. BSI consists of 53 items that must be answered on a 5-point scale $(0=$ Not at all, $4=$ Very much). This scale has nine subscales: somatization, obsessive-compulsive symptoms, interpersonal sensitivity, depression, anxiety, hostility, phobic anxiety, paranoid ideation and psychoticism; and three global indices (Positive Symptom Distress Index, Global Severity Index, and Positive Symptom Total). Increased scores indicate higher psychopathological symptomatology. The Portuguese version of the instrument evidenced good internal consistency and adequate discriminant validity (Canavarro 1999). In the present study, the anxiety subscale ("Feeling frightened") was used to assess the general level of parental anxiety. Satisfactory internal consistency was obtained in this study ( $\alpha=.72$ for fathers and $\alpha=.75$ for mothers).

\section{Statistical Analysis}

All analysis were performed using the Statistical Package of Social Sciences (SPSS, version 22). Cluster analysis was used to explore parenting typologies for mothers and fathers separately based on various parental rearing behaviors as measured by the EMBU-P (i.e., emotional warmth, rejection, control) and PAOS (i.e., overprotection and encouragement of approach behaviors). Note that the PAOS dimension 'anxiety and worry about the child' was excluded from cluster analysis because it measures a specific type of parental anxiety rather than parenting behavior towards the child. Instead, this variable was analyzed as a dependent variable in relation to parent typologies.

Cluster analysis allows the combination of parents into homogeneous groups (i.e., clusters), according to similar characteristics (i.e., parenting styles) (Mooi and Sarstedt 2011). To form clusters, we conducted two related procedures. First, agglomerative hierarchical cluster analysis was initially conducted to establish the number of clusters in the sample, after which K-means procedures were used to group families, classifying each parent into the number of clusters previously determined.

The greatest limitation of cluster analysis (and also with factor analysis) is that there are no standard criteria for choosing the best solution from among the options. They are largely exploratory procedures and the selection must be based on the examination of different cluster solutions and theoretical considerations. The determination of the number of clusters was achieved through hierarchical cluster analysis. This procedure begins with each case as a separate cluster and progressively combines clusters to build a hierarchy of nested clusters until they are combined into only one cluster. The hierarchical algorithm selected was Ward's method because it seems to be the most robust to various types of data (Mandara 2003). In this method, the means for all variables are calculated for each cluster. Then, for each case, the squared Euclidean distance to the cluster means is calculated and these distances are summed for all of the cases. At each step, the two clusters that merge are those that result in the smallest increase in the overall sum of the squared within-cluster distances.

To reach a decision regarding the number of clusters, the resulting graphical representation of the agglomerative hierarchical cluster analysis-or dendrogram-was analyzed. Natural breaks are indicated by larger distances between clusters in each step and suggest the cut-off points to determine the number of clusters. After deciding the potential number of clusters based on the dendrogram and on the theoretical relevance of the resulting clusters, the final number of clusters was decided through a crossvalidation procedure. This cross-validation procedure, suggested by Mandara (2003), consists of a replication analysis to examine the stability of the cluster solution across samples (see Breckenridge 2000) via a five step procedure. Initially, the sample is randomly divided into two samples. Then, a full cluster analysis is performed on one of the samples (sample A). A full cluster analysis is then performed on the remaining subjects from the other sample (sample B). Sample B is then classified into clusters according to the centroids derived from sample A. Finally, the agreement is computed between the two sample B solutions using Cohen's kappa. These steps were repeated ten times (in twenty samples resulting from ten random divisions of the total data in two equal size samples) for each potential number of clusters and the cluster solution with the largest mean Kappa was retained.

After deciding on the best cluster solution, we then computed a K-means cluster analysis using the initial cluster centers obtained from the hierarchical analysis. This method begins with an initial set of means and classifies cases based on their distances to the centers and recalculates their position until no significant difference exists in the minimum distance between each parent and each centroid in the solution (Maroco 2007). After the determination of the number of clusters, the K-means method is preferable to hierarchical cluster analysis because once a case is classified into one cluster in the hierarchical analysis, it cannot be re-grouped into another, which increases the probability of error during the classification process.

To identify which variables were more important in the clusters and to examine the characteristics of the clusters (parental rearing typologies) in terms of various specific parental rearing behaviors, a multivariate analysis of variance (MANOVA) was computed on the five EMBU and 
PAOS scales, with the clusters variable serving as the factor. Post hoc Tukey's HSD multiple and Tahamne's comparisons tests were used for the follow-up comparisons. Furthermore, the obtained mothers' and fathers' rearing typologies were compared with regard to both children's and parents' anxiety symptoms, in addition to parental anxiety or worry about the child. Univariate tests were conducted for mothers' and fathers' data separately to study whether parental clusters differed in terms of child's anxiety (SCARED), parental anxiety (BSI), and parental anxiety and worry about the child (PAOS anxiety/worry) scores. To verify whether relevant demographic variables, such as a child's gender and age, were different for parents' parenting typologies, Chi square tests were performed.

\section{Results}

Agglomerative hierarchical cluster analysis was conducted to determine the interpretable number of clusters for the mothers' and fathers' data separately. The agglomeration schedules and dendograms pointed in the direction of either a three or four cluster solution. Considering the criteria as described in the methods section, a three cluster solution was eventually determined to provide the best fit for the data. High agreement rates were obtained for the three clusters solutions of mothers, Cohen's kappa, $k=.89$, and fathers, $k=.77$. Cohen's kappa computed for the four cluster solutions resulted in considerably lower agreement rates for both mothers, $k=.41$, and fathers, $k=.32$.

The results revealed a significant multivariate effect for mothers' parenting patterns, Roy's Largest Root $=2.038$, $F(5382)=155.67, p<0.001, \eta^{2}=.67$, and for fathers' parenting patterns, Roy's Largest Root $=1.83$, $F(5378)=138.89, p<0.001, \eta^{2}=.65$. Univariate analyses of variance (ANOVAs) were then performed for each cluster to compare the clusters on the variables included in the clustering process. The three maternal and paternal clusters evidenced significant differences in all parenting variables (Tables 1,2). The cluster solutions derived from mothers' and fathers' data were comparable and by and large shared similar parenting characteristics. Based on the most salient characteristics of the clusters, these parenting typologies can be labeled as: (1) Overinvolved, $38.9 \%$ mothers and $37.2 \%$ fathers; (2) Disengaged, $19.3 \%$ mothers and $26.8 \%$ fathers; and (3) Supportive, $41.8 \%$ mothers and $35.9 \%$ fathers.

As expected, pairwise comparisons revealed that the three clusters were quite different in terms of various parenting dimensions. High levels of control, overprotection, and encouragement of approach behaviors were observed in the overinvolved cluster. The disengaged cluster displayed the lowest levels of emotional warmth and encouragement of approach behaviors. The supportive cluster comprised parents characterized by low levels of rejection and overprotection.

To determine whether the three parental clusters differed in terms of demographic variables such as child's gender and age, Chi square tests were performed. No significant relationship was found between the child's gender, on the one hand, and mothers' parenting clusters, $\chi^{2}(2388)=2.25, p=.33$ or fathers' parenting clusters, $\chi^{2}(2384)=3.20, p=.54$, on the other hand. In addition, the distribution of younger and older children was not significantly different across the three clusters of mothers, $\chi^{2}(2388)=2.54, p=.08$, and the three clusters of fathers, $\chi^{2}(2385)=.05, p=.97$.

The results showed the significant effect of mothers' parenting clusters on children's anxiety symptoms, $F(2385)=5.61, p<.01, \eta^{2}=.02$. Post-hoc comparisons indicated that children of disengaged mothers had significantly higher anxiety scores than those of supportive mothers. The overinvolved cluster of mothers did not significantly differ from the other two types in terms of children's anxiety. Further, it was found that fathers' parenting clusters did not differ in terms of children's anxiety symptoms, $F(2383)=.97, p=.37$.

Analyses performed to evaluate differences across parenting clusters and parental anxiety symptoms (BSI) revealed that the three father typologies were different in terms of paternal anxiety symptoms, $F(2379)=8.35$, $p<.01, \eta^{2}=.04$. Post-hoc tests showed that the fathers from the supportive typology have significantly lower levels of anxiety than the disengaged typologies, with no significant differences being observed between the latter two clusters (see Table 3). The father typologies were also different in terms of anxiety and worry about the child $($ PAOS $), F(2381)=116.96, p<.001, \eta^{2}=.38$ : overinvolved fathers were found to display higher levels of anxiety/worry about their child compared with the disengaged and supportive fathers.

The three clusters of mothers were also significantly different in terms of maternal anxiety symptoms, $F(2383)=4.99, p<.01, \eta^{2}=.02$. Post-hoc comparisons indicated that mothers in the disengaged cluster displayed significantly higher levels of anxiety compared with the supportive cluster, with the overinvolved cluster scoring in between but not being significantly different from the other two clusters. Clusters of mothers were also different in terms of anxiety/worry about the child, $F(2385)=79.75$, $p<.001, \eta^{2}=.29$ : overinvolved mothers appeared to be most anxious and worried about their child, followed by disengaged mothers and supportive mothers, who were clearly the least anxious and worried about their offspring. 
Table 1 Means and standard deviations on separate EMBU-P and PAOS scales for the three maternal parenting typologies as obtained with cluster analysis

\begin{tabular}{|c|c|c|c|c|c|c|c|c|c|}
\hline & \multirow[b]{2}{*}{ Range } & \multicolumn{2}{|c|}{$\begin{array}{l}\text { Overinvolved } \\
(n=153)\end{array}$} & \multicolumn{2}{|c|}{$\begin{array}{l}\text { Disengaged } \\
(n=75)\end{array}$} & \multicolumn{2}{|c|}{$\begin{array}{l}\text { Supportive } \\
(n=162)\end{array}$} & \multirow[b]{2}{*}{$F$} & \multirow[b]{2}{*}{$\eta 2$} \\
\hline & & M & SD & M & SD & M & SD & & \\
\hline EMBU-P Emotional warmth & $13-52$ & $48.48^{\mathrm{a}}$ & 3.83 & $38.52^{\mathrm{b}}$ & 4.89 & $49.06^{\mathrm{a}}$ & 3.27 & 215.86 & .52 \\
\hline EMBU-P Rejection & $17-68$ & $28.58^{\mathrm{a}}$ & 4.45 & $27.60^{\mathrm{a}}$ & 3.95 & $25.78^{\mathrm{b}}$ & 3.32 & 20.25 & .09 \\
\hline EMBU-P Control & $11-44$ & $32.69^{\mathrm{a}}$ & 3.29 & $26.49^{\mathrm{b}}$ & 3.95 & $27.19^{\mathrm{b}}$ & 3.64 & 125.55 & .39 \\
\hline PAOS Overprotection & $0-28$ & $18.72^{\mathrm{a}}$ & 3.93 & $10.56^{\mathrm{b}}$ & 4.52 & $8.59^{\mathrm{c}}$ & 3.33 & 229.19 & .59 \\
\hline PAOS Encouragement of approach behaviors & $0-12$ & $9.41^{\mathrm{a}}$ & 2.04 & $6.85^{\mathrm{c}}$ & 3.34 & $8.59^{\mathrm{b}}$ & 3.64 & 32.67 & .15 \\
\hline
\end{tabular}

Significant differences existed between profile groups on all variables $(p<.001)$. Different subscripts within a row indicate significantly different means on post hoc HSD Tukey or Tamhane tests. EMBU-P = Egna Minnen Beträffande Uppfostran-Parent version, PAOS = Parental Anxiety and Overprotection Scale

Table 2 Means and standard deviations on separate EMBU-P and PAOS scales for the three paternal parenting typologies as obtained with cluster analysis

\begin{tabular}{|c|c|c|c|c|c|c|c|c|c|}
\hline & \multirow[b]{2}{*}{ Range } & \multicolumn{2}{|c|}{$\begin{array}{l}\text { Overinvolved } \\
(\mathrm{n}=145)\end{array}$} & \multicolumn{2}{|c|}{$\begin{array}{l}\text { Disengaged } \\
(\mathrm{n}=105)\end{array}$} & \multicolumn{2}{|c|}{$\begin{array}{l}\text { Supportive } \\
(\mathrm{n}=140)\end{array}$} & \multirow[b]{2}{*}{$F$} & \multirow[b]{2}{*}{$\eta 2$} \\
\hline & & M & SD & M & SD & M & SD & & \\
\hline EMBU-P Emotional warmth & $13-52$ & $47.20^{\mathrm{a}}$ & 3.89 & $38.78^{\mathrm{b}}$ & 3.74 & $47.77^{\mathrm{a}}$ & 3.11 & 222.01 & .54 \\
\hline EMBU-P Rejection & $17-68$ & $29.23^{\mathrm{a}}$ & 3.89 & $27.90^{\mathrm{b}}$ & 4.86 & $24.42^{\mathrm{c}}$ & 3.42 & 48.22 & .20 \\
\hline EMBU-P Control & $11-44$ & $31.52^{\mathrm{a}}$ & 3.66 & $25.85^{\mathrm{b}}$ & 3.38 & $24.15^{\mathrm{b}}$ & 3.42 & 101.30 & .35 \\
\hline PAOS Overprotection & $0-28$ & $16.76^{\mathrm{a}}$ & 4.07 & $8.72^{\mathrm{b}}$ & 3.75 & $8.10^{\mathrm{b}}$ & 3.29 & 229.19 & .55 \\
\hline $\begin{array}{l}\text { PAOS Encouragement of approach } \\
\text { behaviors }\end{array}$ & $0-12$ & $9.11^{\mathrm{a}}$ & 2.10 & $6.07^{\mathrm{c}}$ & 2.45 & $7.73^{\mathrm{b}}$ & 2.76 & 46.21 & .20 \\
\hline
\end{tabular}

Significant differences existed between profile groups on all variables $(p<.001)$. Different subscripts within a row indicate significantly different means on post hoc HSD Tukey or Tamhane tests. EMBU-P = Egna Minnen Beträffande Uppfostran-Parent version, PAOS = Parental Anxiety and Overprotection Scale

Table 3 Means and standard deviations on child and parents' anxiety and parental anxiety/worry about child for parenting typologies

\begin{tabular}{lccc}
\hline & $\begin{array}{l}\text { Overinvolved } \\
\text { M (SD) }\end{array}$ & $\begin{array}{l}\text { Disengaged } \\
\text { M (SD) }\end{array}$ & $\begin{array}{l}\text { Supportive } \\
\text { M (SD) }\end{array}$ \\
\hline SCARED—Children anxiety & $48.44(18.73)$ & $52.29(20.3)^{\mathrm{a}}$ & $43.66(19.44)^{\mathrm{b}}$ \\
BSI-Maternal anxiety & $3.83(3.37)$ & $4.49(3.20)^{\mathrm{a}}$ & $3.16(1.89)^{\mathrm{b}}$ \\
BSI-Paternal anxiety & $2.83(2.57)^{\mathrm{a}}$ & $2.92(2.82)^{\mathrm{a}}$ & $1.01(2.57)^{\mathrm{b}}$ \\
PAOS-Maternal anxiety and worry about the child & $25.79(7.27)^{\mathrm{a}}$ & $18.20(7.81)^{\mathrm{b}}$ & $15.52(7.13)^{\mathrm{c}}$ \\
PAOS—Paternal anxiety and worry about the child & $23.60(7.81)^{\mathrm{a}}$ & $13.15(6.36)^{\mathrm{b}}$ & $12.11(6.11)^{\mathrm{b}}$ \\
\hline
\end{tabular}

Significant differences existed between profile groups on all variables $(p<.001)$. Different subscripts within a row indicate significantly different means on post hoc HSD Tukey or Tamhane tests. SCARED$\mathrm{R}=$ Screen for Child Anxiety Related Emotional Disorders (Revised); BSI = Brief Symptoms Inventory; PAOS = Parental Anxiety and Overprotection Scale

\section{Discussion}

A large body of literature links particular parenting dimensions to negative child outcomes, including anxiety problems (Wood et al. 2003). The current study adopted a typological approach to examine how different paternal and maternal rearing styles are associated with children's anxiety, parental anxiety and parents' anxiety/worry about the child. For both parents, three parenting clusters were identified. The first cluster, which was labeled as overinvolved, included parents with relatively high levels of control, overprotection, emotional warmth, and encouragement of approach behaviors. The second cluster, which was defined as disengaged, was characterized by low levels of positive parenting behaviors such as emotional support and encouragement of approach behaviors. The last cluster, 
which was defined as supportive, displayed the lowest levels of overprotection and rejection as well as fairly high levels of emotional warmth.

The cluster solution obtained in this study revealed some similarities with the parenting typologies previously reported in the literature. For example, the overinvolved parenting cluster seems to bear resemblance to the affection-constraint (Parker et al. 1979) and the supportivecontroller (Pereira et al. 2008) typologies. The disengaged cluster has commonalities with the neglecting (Baumrind 1989), the absent or weak bonding (Parker et al. 1979), and the low supportive (Pereira et al. 2008) typologies. Finally, the supportive cluster clearly shares feature with the authoritative (Baumrind 1989), the optimal-bonding (Parker et al. 1979) and the supportive typologies (Pereira et al. 2008). Thus, there may be some universal validity to these parenting clusters, although it should be noted that the outcome of this type of study is of course highly dependent on the parenting behaviors that are used as the inputs for the cluster analysis.

The results indicated that disengaged mothers had children with higher levels of anxiety symptoms. To some extent, this finding is consistent with the results of previous research; that is, lower levels of warmth and positivity are associated with higher levels of childhood anxiety (Dadds et al. 1996; Moore et al. 2004; Whaley et al. 1999). The theoretical model of Bögels and Phares (2008) has also postulated that maternal rejection and lack of acceptance are important correlates of children's anxiety, particularly during middle childhood. Further, researchers have argued that the lack of warmth and acceptance may predispose children to unsafe, unsupportive, and helpless feelings when confronted with novel situations (Luis et al. 2008). The disengaged cluster of mothers was also characterized by low level of maternal control, which according to the literature should normally be associated with lower levels of child anxiety; however, lack of control or its equivalent, excessive granting of autonomy, may have an anxietyprovoking effect in young children (Verhoeven et al. 2012). This may be especially true when combined with low levels of emotional support. Along the same lines, Bögels and Brechman-Toussaint (2006) assume that the relationship between parental control and child anxiety is likely to be curvilinear, which means that both parental under-control and over-control may predispose children to anxiety.

The fathers' disengaged parenting cluster was not associated with higher levels of anxiety symptoms in children. This result is in line with previous research showing that fathers' parenting in general is less clearly related to child anxiety compared with mothers' parenting behaviors (Bögels and Melick 2004; Hudson and Rapee 2002).
Unexpectedly, the overinvolved cluster, and in particular that of mothers, was not associated with higher levels of children's anxiety. One explanation for this finding might be that the nature of parenting may differ as a function of culture (Grusec et al. 1997; Kim and Rohner 2002). Note that the present study was conducted in a Latino country (i.e., Portugal), where controlling, protective and even intrusive rearing practices, in combination with warmth, are considered as normative maternal behaviors (Carlson and Harwood 2003; Pereira et al. 2008). This parenting style has the function of teaching children the cultural values and norms of family life (Grusec et al. 1997; Grusec and Goodnow 1994). Furthermore, even in the overinvolved clusters, levels of control and overprotection were not excessively high. Thus, the non-clinical children included in this research experienced a level of overprotection and control from their parents that did not compromise their abilities to face novel situations or prompt them to develop threat cognitions in relation to their environment (Chorpita and Barlow 1998). This may have been different if we had included clinically referred children and their parents in the current investigation.

When comparing the different parenting clusters regarding parental characteristics, the results show that disengaged fathers and mothers displayed fairly high levels of anxiety symptoms. This result is consonance with previous studies showing that anxious parents are more withdrawn and disengaged than non-anxious parents (Schrock and Woodruff-Borden 2010; Whaley et al. 1999; Woodruff-Borden et al. 2002; Turner et al. 2003). It seems plausible that those parents are more focused on their own anxiety symptoms and their self-regulation, which may compromise their ability to be involved in parenting. As a consequence, some parents might be more dismissive and less actively involved in rearing.

Our findings also indicated that the overinvolved cluster was associated with higher levels of anxiety/worry about the child in both parents. It could be expected that parents who are more worried about the well-being of their child may interpret ambiguous situations as potential threats to the child more frequently (Lester et al. 2012). Those cognitions may evoke controlling and overprotective behaviors, especially if parents perceive their children as anxious (Cobbam et al. 1999) and themselves as unable to cope with difficulties.

In sum, disengaged rearing seems to be associated with both parental and children's anxiety, whereas anxiety/worry about the child seemed more related to overinvolved rearing styles. It is possible that these results reflect different paths to explain parental behavior. Disengaged parents may be withdrawn and less involved in childrearing as a reflex from their anxiety problems and from their difficulty to cope with child distress in a more proactive 
and adjusted manner. In other parents, worry about the child and the corresponding tendency towards overprotecting styles may represent an adaptive attempt to respond to children's needs, which might be relatively normative in childhood, rather than suggestive of the presence of children's or parental anxiety problems. Future studies could clarify this hypothesis.

The present findings must be considered in the context of various limitations. To begin with, as noted earlier, the cross-sectional research design does not allow us to make causal inferences. Further, the sample was communitybased; most families were intact, had a medium level of income, and lived in urban areas. For these reasons, the generalizability of the obtained results may be limited. Another potential shortcoming was that this research relied solely on self-reports to measure parental variables as well as anxiety symptoms, and socially desirable response tendencies cannot be excluded. Finally, we did not include all parenting dimensions that might be relevant to the study of child anxiety. Autonomy granting (McLeod et al. 2007) and rough-and-tumble play (Bögels and Perotti 2010) are noteworthy examples that that must be incorporated in future studies. Given these caveats, a clinical sample should be included in future studies to confirm whether these patterns maintain their characteristics and associations with outcomes of interest. Parental anxiety disorders diagnoses should also be controlled. Parental report of their own parenting behaviors could also be complemented by observational methodologies and by children's and partners' reports to overcome the limitation of self-report methods.

To date, most studies have explored how separate parenting dimensions are related to child anxiety. However, little is known about combinations of parenting behaviors within the context of this type of child psychopathology. With this in mind, the present study employed cluster analysis to identify various parenting typologies, an approach that more fully covers the complex facets of childrearing and provides a better understanding of how patterns of parenting behaviors may influence the development of anxiety disorders. Our findings suggest that disengaged parenting, especially if evidenced by mothers, seems to be a potentially important risk factor for child anxiety. Although this pattern has demonstrated some common features with neglecting styles described in the literature, our disengaged pattern is mostly characterized by two main features: a lack of positive parenting styles and behaviors, such as emotional warmth and encouragement of approach behaviors, and high parental anxiety. These findings might be included in preventive interventions targeting anxious children and their families.
Acknowledgments This work is financed by national funds by FCT-Fundação para a Ciência e Tecnologia by a grant awarded to the first author (SFRH/7737/2011) and under the project PTDC/PSIPCL/122007/2010.

\section{References}

Ballash, N., Leyfer, O., Buckley, A. F., \& Woodruff-Borden, J. (2006). Parental control in the etiology of anxiety. Clinical Child and Family Psychology Review, 9, 113-133.

Barber, B. K. (1996). Parental psychological control: Revisiting a neglected construct. Child Development, 67, 3296-3319.

Barlow, D. H. (2002). Origins of apprehension, anxiety disorders, and related disorders. In D. H. Barlow (Ed.), Anxiety and its disorders: The nature and treatment of anxiety and panic (pp. 252-291). New York: Guilford Press.

Barrett, P. M., Fox, T., \& Farrell, L. J. (2005). Parent-child interactions with anxious children and with their siblings: An observational study. Behaviour Change, 22, 220-235.

Baumrind, D. (1971). Current patterns of parental authority. Developmental Psychology, 4, 1-103.

Baumrind, D. (1989). Rearing competent children. In W. Damon (Ed.), Child development today and tomorrow (pp. 349-378). San Francisco: Jossey-Bass.

Baumrind, D. (1991). The influence of parenting style on adolescent competence and substance use. Journal of Early Adolescence, 11(1), 56-95.

Baumrind, D., Larzelere, R. E., \& Owens, E. (2010). Effects of preschool parents' power assertive patterns and practices on adolescent development. Parenting: Science and Practice, 10(3), 157-201.

Benoit, K. (2009). The relationship between parenting style and childhood anxiety in an ethnically diverse South African sample. Unpublished master's thesis. Virginia Polytechnic Institute and State University, United States.

Bögels, S. M., Bamelis, L., \& van der Bruggen, C. O. (2008). Parental rearing as a function of parent's own, partner's, and child's anxiety status: Fathers make the difference. Cognition and Emotion, 22, 522-538.

Bögels, S. M., \& Brechman-Toussaint, M. L. (2006). Family issues in child anxiety: Attachment, family functioning, parental rearing and beliefs. Clinical Psychology Review, 26, 834-856.

Bögels, S. M., \& Melick, M. (2004). The relationship between childreport, parent self-report, and partner report of perceived parental rearing behaviors and anxiety in children and parents. Personality and Individual Differences, 37, 1583-1596.

Bögels, S. M., \& Perotti, E. C. (2010). Does father know best? A formal model of the paternal influence on childhood social anxiety. Journal of Child and Family Studies, 20, 171-181.

Bögels, S. M., \& Phares, V. (2008). Fathers' role in the etiology, prevention and treatment of child anxiety: A review and new model. Clinical Psychology Review, 28, 539-558.

Breckenridge, J. (2000). Validating cluster analysis: Consistent replication and symmetry. Multivariate Behavioral Research, $35,261-285$.

Canavarro, M. C. (1999). Inventário de Sintomas Psicopatológicos: BSI. In M. R. Simões, M. Gonçalves, \& L. S. Almeida (Eds.), Testes e provas psicológicas em Portugal (pp. 87-109). Braga: SHO/APPORT.

Canavarro, M. C., \& Pereira, A. I. (2007). A avaliação dos estilos parentais educativos na perspectiva dos pais: A versão portuguesa do EMBU-P. Psicologia: Teoria Investigação e Prática, 2, 271-286. 
Carlson, V. J., \& Harwood, R. L. (2003). Attachment, culture, and the caregiving system: The cultural patterning of everyday experiences among Anglo and Puerto Rican mother-infant pairs. Infant Mental Health Journal, 24, 53-73.

Caron, A., Weiss, B., Harris, V., \& Catron, T. (2006). Parenting behavior dimensions and child psychopathology: Specificity, task dependency, and interactive relations. Journal of Clinical Child and Adolescent Psychology, 35, 34-45.

Cartwright-Hatton, S., McNicol, K., \& Doubleday, E. (2006). Anxiety in a neglected population: Prevalence of anxiety disorders in preadolescent children. Clinical Psychology Review, 26(7), 817-833.

Castro, L., Pablo, J., Gomez, J., Arrindell, W. A., \& Toro, J. (1997). Assessing rearing behaviour from the perspective of the parents: A new form of the EMBU. Social Psychiatry and Psychiatric Epidemiology, 32, 230-235.

SPSS. Version 22. Chicago: Author; 2013.

Chorpita, B. F., \& Barlow, D. H. (1998). The development of anxiety: The role of control in the early environment. Psychological Bulletin, 124, 2-3.

Cobham, V. E., Dadds, M. M., \& Spence, S. H. (1999). Anxious children and their parents: What do they expect? Journal of Clinical Child Psychology, 28, 220-231.

Costello, E. J., Mustillo, S., Keller, G., \& Angold, A. (2004). Prevalence of psychiatric disorders in childhood and adolescence. In B. L. Levin, J. Petrila, \& K. D. Hennessy (Eds.), Mental health services: A public health perspective (pp. 111-128). Oxford: Oxford University Press.

Dadds, M. R., Barrett, P. M., Rapee, R. M., \& Ryan, S. (1996). Family process and child anxiety and aggression: An observational analysis. Journal of Abnormal Child Psychology, 24, $715-734$.

Darling, N. (1999). Parenting style and its correlates. ERIC digest. Champaign: ERIC clearinghouse on elementary and early childhood education. Urbana: University of Illinois.

Derogatis, L. R. (1982). Self-report measures of stress. In L. Goldberger \& S. Brenznitz (Eds.), Handbook of stress. New York: Free.

Di Bartolo, P. M., \& Helt, M. (2007). Theoretical models of affectionate versus affectionless control in anxious families: A critical examination based on observations of parent-child interactions. Clinical Child and Family Psychology Review, 10(3), 253-274.

Eley, T. C. (2001). Genetic and environmental influences. In M. W. Vasey \& M. R. Dadds (Eds.), The developmental psychopathology of anxiety (pp. 45-59). Oxford: Oxford University Press.

Fliek, L., Daemen, E., Roelofs, J., \& Muris, P. (2015). Rough-andtumble play and other parental factors as correlates of anxiety symptoms in preschool children. Journal of Child and Family Studies, doi:10.1007/s10826-014-0083-5.

Gar, N. S., Hudson, J. L., \& Rapee, R. M. (2005). Family factors and the development of anxiety disorders. In J. L. Hudson \& R. M. Rapee (Eds.), Psychopathology and the family (pp. 125-145). Oxford: Elsevier.

Gerlsma, C., Emmelkamp, P. M., \& Arrindell, W. A. (1990). Anxiety, depression, and perception of early parenting: a meta-analysis. Clinical Psychology Review, 10, 251-277.

Ginsburg, G. S., Riddle, M. A., \& Davies, M. (2006). Somatic symptoms in children and adolescents with anxiety disorders. Journal of the American Academy of Child and Adolescent Psychiatry, 45, 1179-1187.

Grusec, J. E., \& Goodnow, J. J. (1994). Impact of parental discipline methods on the child's internalization of values: A reconceptualization of current points of view. Developmental Psychology, $30,4-19$.
Grusec, J. E., Rudy, D., \& Martini, T. (1997). Parenting cognitions and child outcomes: An overview and implications for children's internalization of values. In J. E. Grusec \& L. Kuczynski (Eds.), Parenting and children's internalization of values: A handbook of contemporary theory (pp. 259-282). New York: Wiley.

Hirshfeld, D. R., Biederman, J., Brody, L., Faraone, S. V., \& Rosenbaum, J. F. (1997). Expressed emotion toward children with behavioral inhibition: Associations with maternal anxiety disorder. Journal of the American Academy of Child and Adolescent Psychiatry, 36(7), 910-917.

Holmbeck, G., Johnson, S., Wills, K., McKernon, W., Rose, B., Erklin, S., \& Kemper, T. (2002). Observed and perceived parental overprotection in relation to psychosocial adjustment in preadolescents with a physical disability: The mediational role of behavioral autonomy. Journal of Consulting and Clinical Psychology, 70, 96-110.

Hudson, J. L. (2013). Parent-child relationships in early childhood and development of anxiety \& depression. In R. M. Rapee, R. E. Tremblay, M. Boivin, \& P. R. DeV (Eds.), Encyclopedia on early childhood development (pp. 1-6). Montreal: Centre of Excellence for Early Childhood Development and Strategic Knowledge Cluster on Early Child Development.

Hudson, J. L., \& Rapee, R. M. (2002). Parent-child interactions in clinically anxious children and their siblings. Journal of Clinical Child \& Adolescent Psychology, 31, 548-555.

Kim, D., \& Rohner, R. P. (2002). Parental warmth, control, and involvement in schooling predicting academic achievement among Korean American adolescents. Journal of Cross-Cultural Psychology, 33, 127-140.

Krohne, H. W. (1992). Developmental conditions of anxiety and coping: A two process model of child rearing effects. In $\mathrm{K}$. A. Hagvet (Ed.), Advances in test anxiety research (pp. 143-155). Lisse: Swets \& Zeitlinger.

Last, C. G., Hersen, M., Kazdin, A. E., Francis, G., \& Grubb, H. J. (1987). Psychiatric illness in the mothers of anxious children. American Journal of Psychiatry, 144, 1580-1583.

Leaper, C. (2002). Parenting girls and boys. Handbook of parenting: Children and parenting (pp. 189-225). Mahwah, NJ: Lawrence Erlbaum Associates Publishers.

Lester, K., Field, A. P., \& Cartwright-Hatton, S. (2012). Maternal anxiety and cognitive biases towards threat in their own and their child's environment. Journal of Family Psychology, 26(5), $756-766$

Luis, T., Varela, R. E., \& Moore, K. (2008). Parenting practices and childhood anxiety reporting: A comparison of Mexican, Mexican American, and European American youth. Journal of Anxiety Disorders, 22, 1011-1020.

Maccoby, E. E., \& Martin, J. (1983). Socialization in the context of the family: Parent - child interaction. In P. H. Mussen (Series Ed.) \& E. M. Hethrington (Vol. Ed.), Handbook of child psychology: Socialization, personality, and social development (4th ed., pp. 1-101). New York: Wiley.

Mandara, J. (2003). The typological approach in child and family psychology: A review of theory, methods and research. Clinical Child and Family Psychology Review, 6, 129-146.

Maroco, J. (2007). Análise Estatística: com utilização do SPSS. Lisbon: Edições Sílabo.

McBride, B. A., \& Mills, G. (1993). A comparison of mother and father involvement with their preschool age children. Early Childhood Research Quarterly, 8, 457-477.

McLeod, B. D., Wood, J. J., \& Weisz, J. R. (2007). Examining the association between parenting and childhood anxiety: A metaanalysis. Clinical Psychology Review, 27, 155-172.

Mooi, E., \& Sarstedt, M. (2011). A concise guide to market research: The process, data, and methods using IBM SPSS statistics. Berlin: Springer. 
Moore, P. S., Whaley, S. E., \& Sigman, M. (2004). Interactions between mothers and children: Impacts of maternal and child anxiety. Journal of Abnormal Psychology, 113(3), 471-476.

Mounts, N. S., \& Steinberg, L. (1995). An ecological analysis of peer influence on adolescent grade point average and drug use. Developmental Psychology, 31, 915-922.

Muris, P., Merckelbach, H., Schmidt, H., \& Mayer, B. (1999). The revised version of the screen for child anxiety related child psychiatry disorders (SCARED-R): Factor structure in normal children. Personality and Individual Differences, 26, 99-112.

Paquette, D. (2004). Theorizing the father-child relationship: Mechanisms and developmental outcomes. Human Development, 47, 193-219.

Parker, G. (1983). Parental 'affectionless control' as an antecedent to adult depression. A risk factor delineated. Archives of General Psychiatry, 40, 956-960.

Parker, G., Tupling, H., \& Brown, L. B. (1979). A parental bonding instrument. British Journal of Medical Psychology, 52, 1-10.

Pereira, A. I., Barros, L., \& Beato, A. (2013). Parental anxiety and overprotection scale: A psychometric study with a sample of parents of school age-children. Revista Iberoamericana de Diagnóstico y Evaluación Psicológica, 35(1), 35-55.

Pereira, A. I., Barros, L, Mendonça, D., \& Muris, P. (2014). The relationships among parental anxiety, parenting, and children's anxiety: The mediating effects of children's cognitive vulnerabilities. Published online. Journal of Child and Family Studies.

Pereira, A. I., Barros, L, \& Neves, M. (2011). The evaluation of anxiety symptomatology in the perspective of the child and the parents: The development of the Portuguese versions of $S C A R E D-R$. Actas do VIII Congresso IberoAmericano de Avaliação Psicológica/XV Conferência Internacional Avaliação Psicológica: Formas e Contextos. Lisboa: Faculdade de Psicologia da Universidade de Lisboa.

Pereira, A. I., Canavarro, C., Cardoso, M., \& Mendonça, D. (2008). Patterns of parental rearing styles and child behaviour problems among Portuguese school-aged children. Journal of Child and Family Studies, 18, 454-464.

Quintin, P. E. (2001). Chamgements familiaux à long terme à la suite d'une intervention écosystémique. In J. Torrente (Ed.), ( Org), La maltraitance-Regars pluridisciplinaires (pp. 191-214). Revigny-sur-Ornain: Hommes et Perspectives.

Radziszewska, B., Richardson, J. L., Dent, C. W., \& Flay, B. R. (1996). Parenting style and adolescent depressive symptoms, smoking, and academic achievement: Ethnic, gender, and SES differences. Journal of Behavioral Medicine, 19(3), 289-305.

Rapee, R. (1997). Potential role of childrearing practices in the development of anxiety and depression. Clinical Psychology Review, 17(1), 47-67.

Rapee, R. M. (2002). The development and modification of temperamental risk for anxiety disorders: Prevention of a lifetime of anxiety? Biological Psychiatry, 52, 947-957.
Schrock, M., \& Woodruff-Borden, J. (2010). Reciprocal patterns of interactions in anxious families. Child and Family Behavior Therapy, 32(4), 291-310.

Steinberg, L., Lamborn, S., Darling, N., Mounts, N., \& Dornbusch, S. M. (1994). Over-time changes in adjustment and competence among adolescents from authoritative, authoritarian, indulgent, and neglectful families. Child Development, 65, 754-770.

Thomasgard, M., \& Metz, W. P. (1993). Parental overprotection revisited. Child Psychiatry and Human Development, 24, 67-80.

Thomasgard, M., \& Metz, W. P. (1997). Parental overprotection and its relation to perceived child vulnerability. American Journal of Orthopsychiatry, 67(2), 330-335.

Turner, S. M., Beidel, D. C., \& Epstein, L. H. (1991). Vulnerability and risk for anxiety disorders. Journal of Anxiety Disorders, 5, $151-166$

Turner, S. M., Beidel, D. C., Roberson-Nay, R., \& Tervo, K. (2003). Parenting behaviors in parents with anxiety disorders. Behaviour Research and Therapy, 41, 541-554.

van der Bruggen, C. O., Stams, G., \& Bögels, S. M. (2008). Research review: The relation between child and parent anxiety and parental control: a meta-analytic review. Journal of Child Psychology and Psychiatry, 49, 1257-1269.

Verhoeven, M., Bögels, S., \& van der Bruggen, C. (2012). Unique roles of mothering and fathering in child anxiety: Moderation by child's age and gender. Journal of Child and Family Studies, 21(2), 331-343.

Weiss, L. H., \& Schwarz, J. C. (1996). The relationships between parenting types and older adolescents' personality, academic achievement, adjustment and substance use. Child Development, 67, 2101-2114.

Weissman, M. M., Feder, A., Pilowsky, D. J., Olfson, M., Fuentes, M., Blanco, C., \& Shea, S. (2004). Depressed mothers coming to primary care: Maternal reports of problems with their children. Journal of Affective Disorders, 78, 93-100.

Whaley, S. E., Pinto, A., \& Sigman, M. (1999). Characterizing interactions between anxious mothers and their children. Journal of Consulting and Clinical Psychology, 67, 826-836.

Wood, J. J. (2006). Parental intrusiveness and children's separation anxiety in a clinical sample. Child Psychiatry and Human Development, 37, 73-87.

Wood, J. J., McLeod, B. D., Sigman, M., Hwang, W. C., \& Chu, B. C. (2003). Parenting and childhood anxiety: Theory, empirical findings, and future directions. Journal of Child Psychology and Psychiatry, 44, 134-151.

Woodruff-Borden, J., Morrow, C., Bourland, S., \& Cambron, S. (2002). The behavior of anxious parents: Examining mechanisms of transmission of anxiety from parent to child. Journal of Clinical Child \& Adolescent Psychology, 31(3), 364-374. 